the light curve of the star by a Fourier series and to determine the fundamental period of the Fourier series. As a test of the practicability of this method, a set of Fath's observations of I2 Lacertae was analyzed. Fath has shown that there are at least three incommensurate periods of variation in the light curve of this star. The first test, using a Fourier series in the primary period alone, showed a very slow rate of convergence. The second test, using a Fourier series in both the primary and secondary periods, converged in six iterations.

In the case of the successful test, the approximating series used was

$$
\begin{aligned}
m=m_{0}+a_{1} \sin \omega_{1} t+a_{2} & \cos \omega_{1} t \\
& +a_{3} \sin \omega_{2} t+a_{4} \cos \omega_{2} t
\end{aligned}
$$

This equation was linearized by expanding in a Taylor's series around a point in the seven dimensional parameter space and neglecting all terms of second or higher order. The result of this expansion gave a linear equation in the seven first-order corrections to be applied to the assumed parameters in order to obtain the solution. This observational equation was then evaluated for each of 132 observations, and the set of 132 observational equations in seven unknows solved by the standard least-squares technique. Since the observational equations used were linear ap- proximations to the true non-linear equations, the solution yields a better approximation to the parameters rather than the best approximation. By successive iterations, however, the leastsquares solution of the non-linear equation can be approached.

This process becomes practicable when rapid computing equipment is available. The tests in question were made on an International Business Machines card-programmed calculator. Each iteration took about six hours, and another three hours were spent in setting up the problem on the machine. A total of one week's work gave a seven parameter fit to 132 observations with a precision of one part in five million for the periods and better than one part in ten thousand in the amplitudes.

\section{National Bureau of Standards} Washington, D. C.

TITLES OF ADDITIONAL PAPERS PRESENTED AT THE MEETING IN HAVERFORD, PA.

Bates, David R., and Lyman Spitzer, Jr. Interstellar and circumstellar molecules.

Eggen, Olin J. Types of stellar population.

Greenstein, Jesse L. Some isotope problems in the sun.

Hetzler, Charles. A definition of temperature.

Keenan, Philip C. HD 26-an unusual $C H$ star.

Omer, Guy C., Jr. The use of the Gram-Charlier series in Plummer's integral equation.

Woodward, Edith Jones. Three W Ursae Majoris type binaries with changing periods.

\title{
THE ECLIPSING VARIABLE SVS 995 ANDROMEDAE
}

\section{By JOSEPH ASHBROOK}

This star is $\mathrm{BD}+40^{\circ} 442(8.5)=\mathrm{HD} \quad \mathrm{I} 3078$ (Go). Its variability was discovered in 1945 by A. Soloviev, ${ }^{1}$ who reported Algol-type variation with the photographic range 8.2-9.5. He published four approximate times of minimum, but failed to find the period. I have not seen any other reference to this star as a variable.

The light variations have been confirmed by an examination of about 200 Harvard patrol plates, which are only a fraction of the total number available, and by visual observations at the Yale Observatory. This material yielded 25 additional minima. SVS 995 Andromedae is a $\beta$-Lyrae variable with the elements

$$
\begin{aligned}
& \text { JD hel. } \min _{1}=24 \mathrm{I} 4688.568+\mathrm{od}^{\mathrm{d}} 6 \mathrm{IoI} 232 \mathrm{E} \\
& \pm .009 \pm .00000042 \text { (m.e.) } \\
& \qquad \begin{array}{c}
\mathrm{M}=8.6, \mathrm{~m}_{1}=9.5, \mathrm{~m}_{2}=9.0 \text { (vis) }
\end{array}
\end{aligned}
$$

The representation of the observed minima by this formula is exhibited in Table I. Here the symbols H, S, and Y indicate Harvard, Stalinabad and Yale observations, respectively. The Stalinabad minimum 2431708.18 is discordant. It has been omitted in the period determination, since no details which might explain its disagreement are available. The mean error of the remaining minima is $\pm 0^{\mathrm{d}}$.024. The period has remained constant within narrow limits over the interval I 899 to 1950 .

\begin{tabular}{rccc}
\multicolumn{1}{c}{ TABLE I. OBSERVED MINIMA OF SVS 995} \\
\multicolumn{1}{c}{ Hel. J.D. } & & \\
$\mathrm{E}$ & $2400000+$ & $\mathrm{O}-\mathrm{C}$ & Observatory \\
$\mathrm{o}$ & I 4688.54 & $-\mathrm{Od} .03$ & $\mathrm{H}$ \\
456 & I 4966.78 & -.00 & $\mathrm{H}$ \\
974 & I5282.80 & -.02 & $\mathrm{H}$ \\
2759 & I637I.88 & $+.0 \mathrm{I}$ & $\mathrm{H}$ \\
3560 & I6860.55 & -.02 & $\mathrm{H}$
\end{tabular}




\begin{tabular}{|c|c|}
\hline $\mathrm{E}$ & $\begin{array}{l}\text { Hel. J.D. } \\
2400000+\end{array}$ \\
\hline 4065 & I 7168.67 \\
\hline 6317 & I 8542.70 \\
\hline 9938 & 20751.89 \\
\hline 10023 & 20803.74 \\
\hline 10492 & 21089.86 \\
\hline 13529 & 22942.79 \\
\hline 13655 & 23019.65 \\
\hline I 5368 & $24064 \cdot 77$ \\
\hline $20765^{\frac{1}{2}}$ & 27357.88 \\
\hline 22642 & 28502.68 \\
\hline 23907 & $29274 \cdot 5^{\mathrm{I}}$ \\
\hline 25599 & 30306.79 \\
\hline 25628 & 30324.54 \\
\hline 25652 & 30339.17 \\
\hline $2607 \mathrm{I}$ & 30594.82 \\
\hline 26076 & 30597.83 \\
\hline 26157 & 30647.25 : \\
\hline 26729 & $30996.25:$ \\
\hline $26860 \frac{1}{2}$ & $31076.5^{2}$ \\
\hline 27454 & 31438.60 \\
\hline 27896 & (3I708. I 8$)$ \\
\hline 30901 & 3354 I.65 \\
\hline 30950 & 3357 I. 57 \\
\hline 30968 & $335^{82} \cdot 54$ \\
\hline
\end{tabular}

$\begin{array}{cc}\text { O-C } & \text { Observatory } \\ +.00 & \mathrm{H} \\ +.05 & \mathrm{H} \\ +.03 & \mathrm{H} \\ +.02 & \mathrm{H} \\ -.0 \mathrm{I} & \mathrm{H} \\ +.0 \mathrm{I} & \mathrm{H} \\ .00 & \mathrm{H} \\ . .00 & \mathrm{H} \\ +.02 & \mathrm{H} \\ -.05 & \mathrm{H} \\ -.0 \mathrm{I} & \mathrm{H} \\ -.04 & \mathrm{H} \\ +.0 \mathrm{I} & \mathrm{H} \\ +.00 & \mathrm{~S} \\ +.0 \mathrm{I} & \mathrm{H} \\ -.03 & \mathrm{H} \\ -.03: & \mathrm{S} \\ +.00: & \mathrm{S} \\ +.03 & \mathrm{H} \\ +.0 \mathrm{I} & \mathrm{H} \\ (.08) & \mathrm{S} \\ +.00 & \mathrm{Y} \\ +.03 & \mathrm{Y} \\ +.0 \mathrm{I} & \mathrm{Y}\end{array}$

The variable is the brighter component of the visual double star ADS I67I $=\Sigma 2$ I5. The wide separation, $20^{\prime \prime}$, and the relative faintness of the components suggest that the pair is optical, but the proper motion is too small to allow a decisive test. From Miczaika's ${ }^{2}$ photometric determination $\Delta m=2.32$, the visual magnitude of the companion is about II.

\section{REFERENCES}

I. Astr. Circ. Acad. Sci. U.S.S.R. No. 44, 1945.

2. Veröff. Bad. Land.-Stw. Heidelberg (Königstuhl) 15, 63, I947.

Yale University Observatory, New Haven, Conn., 1950 November.

\section{THE PARALLAX OF ADS 61}

FROM PHOTOGRAPHS TAKEN WITH THE 24-INCH SPROUL REFRACTOR

\section{By H. ROTH}

ADS 6I $=\Sigma_{3062 ;} \mathrm{o}^{\mathrm{h}} \mathrm{I}^{\mathrm{m}} \cdot \mathrm{O},+57^{\circ} 53^{\prime}$ (I900) is a visual binary with the period I06.83 years and semi-axis major I".43, with combined visual magnitude 6 . Io and spectrum $\mathrm{G}_{3}$; the magnitude difference $^{1}$ between the components $\Delta m=.74$ \pm .03 (p.e.). The first Sproul parallax series extends from I9I2 to I9I5. Photographs of the star have been taken in I922, I926 and I927; from 1938 on, the star was photographed each year except in 1942 and I946. Periastron was passed in $\mathrm{I} 943$.

Measures on 90 plates with 292 exposures (total weight is 75) taken on 49 nights give the value +".0466 \pm ".0055 (p.e.) for the relative parallax and +".376 \pm ".020 for the semi-axis major of the photocentric orbit. The results from a combined solution of the measurements in right ascension $(x)$ and declination $(y)$ are:

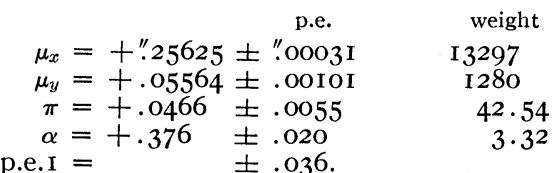

The present value of the parallax supersedes the early Sproul determination +".030土".008 which was based on I 2 plates, I I of which were included in the present investigation. ${ }^{2}$ Reduced to absolute, the Sproul value of the parallax of ADS 6I is +".050. Other photographic values, adjusted for Schlesinger's precepts, ${ }^{3}$ are +".oo8 \pm ".or5 (Yerkes), ${ }^{4}+$ ".oor \pm ".oro (McCormick), ${ }^{5}$ and +".060土".006 (Allegheny). ${ }^{6}$ No systematic corrections were applied to the Sproul absolute parallax value and the probable error given above. On the basis of the probable errors, the weighted mean result of the available photographic parallax determinations of $\mathrm{ADS} 6 \mathrm{I}$ is + ".0483 \pm ".0039. However, we get the probable error \pm ".0076 if we take into account the deviations from the mean value.

The images on the early plates between I9I2 and 1927 are slightly elongated and therefore the present material is not adequate to secure a definite result on the mass-ratio. Nevertheless the calculation was carried out. The fractional mass of the companion is obtained from the relation $\mathrm{B}=\frac{\alpha}{a}+\beta$.

$$
\begin{gathered}
\text { P. Baize's }{ }^{7} \text { orbit gives } a=\mathrm{I} " .43 \text {, whence } \\
\mathrm{B}=+.263+\beta .
\end{gathered}
$$

With Muller's ${ }^{1}$ value $\Delta m=.74 \pm .03$ we derive $^{8} \beta=.336 \pm .006$ and hence $\mathrm{B}=+.599$ \pm .oI 5 . The adopted parallax + ".o48 yields $2.3 \odot$ for the sum of the masses of the components. Hence the mass of $\operatorname{ADS} 6 \mathrm{I} A$ is $.9 \odot$, that of ADS $6 \mathrm{I}$ B is $\mathrm{I} .4 \odot$. 